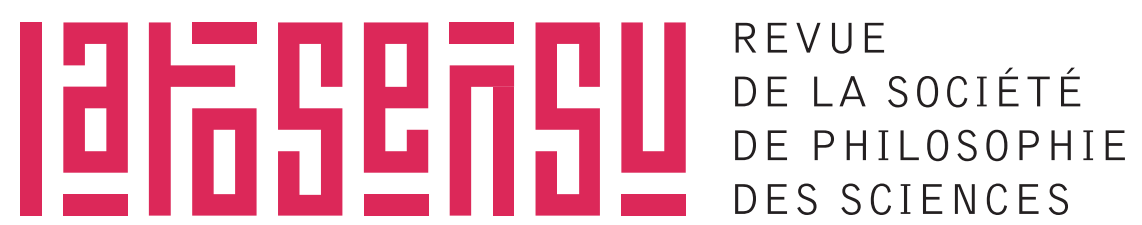

Vol $5 N^{\circ} 12018$

http://dx.doi.org/10.20416/lsrsps.v5i1.2

Cliff Hooker

RE-MODELLING

SCIENTIFIC

CHANGE: COMPLEX

SYSTEMS FRAMES

INNOVATIVE

PROBLEM SOLVING

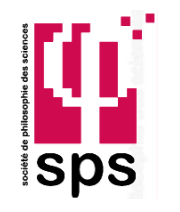

SOCIÉTÉ DE PHILOSOPHIE DES SCIENCES (SPS) 


\section{RE-MODELLING SCIENTIFIC CHANGE: COMPLEX SYSTEMS FRAMES INNOVATIVE PROBLEM SOLV-}

\section{ING}

\author{
Sommaire \\ 1 - Introduction \\ 2 - Q1. What are the \\ consequences, for science, of \\ science using and studying \\ complex systems? \\ 3- Q2. What are the \\ consequences, for philoso- \\ phy of science, of science \\ using and studying complex \\ systems? \\ 4-Q3. What are the \\ consequences, for philosophy \\ of science, of philosophy of \\ science modelling science as a \\ complex system? \\ 5 - Conclusion
}

\begin{abstract}
Complex systems are used, studied and instantiated in science, with what consequences? To be clear and systematic in response it is necessary to distinguish the consequences, (i) for science, of science using and studying complex systems, (ii) for philosophy of science, of science using and studying complex systems, (iii) for philosophy of science, of philosophy of science modelling science as a complex system. Each of these is explored in turn, especially (iii). While (iii) has been least studied, it will be shown how modelling science as a complex process may change our conception of science and thereby query what a philosophy of science adequate to this complexity might look like.
\end{abstract}

Key-words: systems paradigm, problem solving, scientific research, self-directed anticipative

\section{1 - Introduction}

Complex systems are used, studied and instantiated in science. What are the consequences of this? For clarity, distinguish the following, partly interrelated, questions:

Q1. What are the consequences, for science, of science using and studying complex systems?

Q2. What are the consequences, for philosophy of science, of science using and studying complex systems?

Q3. What are the consequences, for philosophy of science, of philosophy of science modelling science as a complex system?

In what follows these questions will be addressed, in order, with more attention given as we proceed since, while none of these questions has well established responses, they are numbered from best to least understood. With respect to the discovery and subsequent permeation of complex systems throughout science over the past roughly 70 years, Q1 inquires about the impact this has had on doing science, for instance on constructing scientific models, methods and explanations. Q2, by contrast, focuses on the impact of these developments on philosophy of science, for instance in a possible separation of explanation from prediction, or a new model of emergence. Finally, Q3 is concerned with whether science itself is a complex system in important respects and how this might change our conception of science and thereby query what a philosophy of science adequate to this complexity might look like. There is a corresponding line of questions that pertain to social science modelling, including of science, for example concerning complexity in economic models of science; but given the huge, very diverse and uneven, literatures involved, and the present constraints on space, they will not be pursued here.

\section{2 - Q1. What are the conse- quences, for science, of sci- ence using and studying com- plex systems?}

Complex systems are not simply a new collection of empirical models alongside all the others as, say, replacing traffic signals with roundabouts might be added to traffic-flow models without introducing any new fundamental ideas. Rather, they have introduced many new concepts and models to science that have irrevocably expanded its models, theories and methods. This is no place to begin to set out a systematic review of these, which would be at least book-length in scope and is in any case largely now available elsewhere (see Hooker (2011a), and references). Here the point will be briefly illustrated by listing just some of the new concepts and methods involved so as to indicate the distinctive impact of the new ideas, without claiming completeness or attempting grander abstractions. What follows is drawn from Hooker (2011a), especially (2011b). References to system states are to dynamical conditions and behaviours; cognitive states and functional states more generally are a further matter. Interested readers are invited to follow up the ideas in the literature (above). 


\section{RE-MODELLING SCIENTIF- IC CHANGE: COMPLEX SYS- TEMS FRAMES INNOVATIVE PROBLEM SOLVING}

\section{Complex Systems Concepts}

- $\quad$ bifurcations - shifts of system state that are also shifts of dynamical form (e.g. phase changes from solid to liquid to gas).

- $\quad$ criticality - a state in which the distribution of fluctuations is scale-invariant (big and small changes equally probable).

- global constraints - constraints whose satisfaction requires system-wide interdependencies (e.g. a machine all of whose diverse parts must fit properly together to work).

- self-organisation - formation of a new system constraint and consequent new orderedness (e.g. formation of new crystalline constraint in phase change from liquid to solid).

- $\quad$ stochasticity (non-quantal) - inherent system fluctuations in a strange attractor (chaos), or near to one: 'pink' (1/f) emission spectrum (size of changes decreases as their frequency increases).

\section{Complex Systems Methods}

- attractor basin analysis - global dynamical representations, including system stability domains (system locked into a repeating state sequence), near-boundary stability analysis (where fluctuations may transfer systems across basin boundaries) and close bifurcation boundaries (containing closely inter-packed points from touching basins), and transitions between different possible dynamical forms (as basin deformations).

- model-centredness - digital simulation of equation-specified dynamics in the absence of solving dynamical equations in known algebraic functions (e.g. sine waves).

- multi-agent dynamics - simulate collective processes (e.g. bee or termite colonies) as the outcomes of interaction rules among their members (e.g. bees, termites), including cases where intermediary sub-collective organisation emerges (network theory, e.g. 'small worlds' that dominate collective processes).

- stochastic analysis - non-standard statistical analyses, including complexity-generated 'fat-tailed' fluctuations (more highly improbable events than a completely random distribution could be expected to generate).

There is as yet no nice consolidation of these and other concepts and methods into something that could be called a new unified paradigm for doing science. Nonetheless, distinctive concepts, methods, and explanatory foci (see below), accompanied by now with hundreds of empirically supported exemplars that pre-complexity analysis cannot treat, are the stuff of paradigm formation, suggesting that a new paradigm may be forming.

\section{3 - Q2. What are the conse- quences, for philosophy of science, of science using and studying complex systems?}

These consequences essentially fall into two categories, issues for epistemology and method, and issues for metaphysics. The former are arguably the more philosophically significant and will be treated first. Once again, in place of book-length exposition just some of the new concepts will be briefly listed so as to indicate the distinctive impact of the new ideas, without claiming completeness or attempting grander abstractions. What follows is drawn from Hooker (2011c) and other chapters in (2011a).

\section{Complex Systems Epistemology}

- $\quad$ Condition-dependence - the idea that, since dynamics can transform its own form as systems evolve/develop, the laws governing a system can change as it nears such bifurcation states and thus be state-dependent and so also state-dependent will be correlative generalisation, explanation and error (kinds, quantities).

- Explanation with constrained prediction, and vice versa - includes attractor basin identification versus trajectory knowledge, including trajectories for 'strange' attractors (chaos) and inter-basin transitions.

- $\quad$ Intelligibility versus predictability - Machine Learning (prediction for complex systems but non-interpretable internal generating states) versus physical modelling (physical intelligibility but low predictability for complex systems). See further Hooker and Hooker (2017).

- Limits to mathematical representation, and digital simulation - work done against constraints, for instance in self-organisation, for which there is no Lagrangian or Hamiltonian representation of dynamics; where round-up errors swamp dynamical distinctions, including simulation of fine-grained trajectories (e.g. in bifurcations); (more generally) unavailability of known mathematical solution functions for equation sets.

- Poly-ocular perspectivalism - various different ways to specify dynamics, including partial versus whole (e.g. confined to one basin), idealised (collapsing out dynamical structures) or not. (NB: this perspectivalism is distinct from metaphysical versions.)

- Societal explanatory orientation - from static structures (e.g. timeless religious or governance institutions) to contingent dynamical equilibria (e.g. where long term processes like social inequity and ecological degeneration bring about system disruption and transformation, see further below.) ${ }^{1}$

\section{Complex Systems Metaphysics}

- Decomposition and unification - see emergence/reduction, identity and causality entries below.

- Emergence/reduction relations - not opposites but inter-dependent complements understood via constraints and constraint formation (see self-organisation under Q1 above), a dynamical, not logical, relation (note 2).

- Identity criteria - standard options, like sameness of persisting components, fail because function, causal power and component stability can all be changed through dynamical bifurcation (self-organisation, etc.), suggesting sameness of dynamical landscape trajectory as a basis for identity (cf. determinism below).

- Restricted causality; determinism versus causality - causality is not applicable to self-organisation and emergence since a new identity is formed, yet determinism continues to apply; feedback and transformation displace structural with dynamical process concep- 
REVUE

DE LA SOCIÉTÉ

DE PHILOSOPHIE

DES SCIENCES

\section{RE-MODELLING SCIENTIF- IC CHANGE: COMPLEX SYS- TEMS FRAMES INNOVATIVE PROBLEM SOLVING}

tions. $^{2}$

Each of these entries deserves extended discussion. Instead, just explanatory orientation will be considered in a little more detail to better indicate its impact on traditional methodology and, especially here, on epistemology. (See Hooker (2011c, §5.3). Compare, e.g., Gao and Herfel (2011) on ecological analysis, Herfel, Gao and Rodrigues (2011) on traditional Chinese medicine, and Brinsmead and Hooker (2011) for its impact on policy, the counterpart to method.)

Prior to the dynamical perspective introduced by complex systems it was common to assume a stasis-and-disruptivestep-returning-to-new-stasis model of change. For Kuhn, for instance, scientific change falls into two kinds. (A) Intra-stage puzzle-solving under a fixed paradigm, marked by small variations and low-level impacts. (B) Inter-stage revolutions marked by large changes of concepts, principles and methods as well as data, with stases mutually incommensurable. The (A) changes are assumed logical, so considered rational; the (B) changes are non-logical, so considered non-rational. Such dichotomising was common at the time, for example Evolutionary Punctuated Equilibria (Gould and Elderedge, 1977), Climax Ecology (Clements (1928)/1973, cf. Gunderson and Holling 2002), Developmental Psychology (Piaget 1957, cf. Hooker 1994), Dialectic (Marx - see https://en.wikipedia.org/wiki/Dialectic\#Marxist dialectic) and Archeological Succcession (van der Leeuw 2004). In pre-systems times (before 1960, say) this schema for understanding was close to an assumed explanatory paradigm. Toulmin's principles of natural order (1961) even called for its basis to be exempt from explanation, qua presupposed.

By contrast, in a dynamical systems context, a stasis is a dynamical (not passive) equilibrium, that is, a condition stabilised by the remaining ongoing system processes, as waves in river rapids are sustained by the water flow itself. Such dynamical stabilities are resilient against some perturbations or changes to system conditions (e.g. a kayak oar dipped into the river) but are alterable by others (e.g. a fallen rock partially blocking flow). Hence the focal issues shift from determining whether stasis or revolution applies to instead determining the dynamical systems features that predominately explain system behaviours. This occasions a shift from extracting common stage uniformities from data on diverse cases to acquiring data on (i) variabilities in phase, interaction, output, and so on, (ii) differing equilibrium types (static/dynamic, stable/meta-stable, dissipation/constraint driven ...), and (iii) dynamical landscape dependencies (closures, self-organisation, ...). The staircase of stages is replaced by a dynamical system path across a dynamic landscape of multiple attractor kinds, each kind representing an arrangement, of ecology or of culture and governance, etc., that has its own resilient stabilising features (e.g. water regulation, wealth rewards) but also its particular vulnerabilities to perturbations (e.g. water regulation rupture in extended drought, stress produced by social inequity). Movement along the system path is driven by external inputs (e.g. trade, conflict) and internal variation (e.g. in cultural groups, in water resources, in traded goods) and can show all of the complexities expressed in dynamical landscapes, for example small errors or inadequacies that can be amplified to major crises and self-organisation that generates and reinforces new social divisions. In such dynamic landscapes change is characterised by sub-optimality ('good enough to function') and non-uniformity, rather than the optimality and uniformity of the fixed stages. Data collection methods change to be adequate to system identification in dynamical terms (above), dynamical landscape analysis methods change to be adequate to understanding system behaviour. This too is the stuff of paradigm change. ${ }^{3}$

\section{4 - Q3. What are the conse- quences, for philosophy of sci- ence, of philosophy of science modelling science as a com- plex system?}

Though currently few philosophers of science approach science as a complex system, let us this once begin on that basis. Then the consequences are of two kinds: consequences for how science itself is most insightfully modelled, and consequences for formulating a philosophical paradigm for understanding science, that is, for rationalising scientific knowledge, within that approach. The former is a deep but young problem, scarcely addressed. It will receive only an initial and challenging, characterisation here. The latter is still less developed but only because it has been dominated by the inadequate answer of analytic orthodoxy. Setting this latter aside, a very different, but I think more compelling, and somewhat original, proposal will present itself and be developed.

\subsection{Q3(I): How is science itself most insightful- ly modelled? \\ Or, crudely, what is to replace the Kuhnian staircase? Science is clearly a highly dynamical process, undergoing constant change, much of it self-generated, and across a huge range of time scales, from the 300 year examination of Mercury's orbit, to the 30 year development of Ape language research (see below), to the min- ute-by-minute conduct of an experiment. In that context, longer term processes set the constraints for shorter term processes, for instance an experiment will in general accept the tools, methods and finances to hand. Modelling science might then begin by characterising three longer-term partial modelling frameworks, or PFrames, for characterising science:}

PFrame 1. Three quasi-independent, accumulative processes that provide critical resources for science: technology, perception, proto-theory. (I) Perception. Across the centuries science has been correcting (glasses, monitoring), augmenting (micro-, tele- scopes), and replacing (radio-telescopes, ultra-sonogra-

2 - An ontological Perspectivalism may also be adopted where systems ontology is theorised as a composite of ontologically distinct and possibly incompatible partial perspectives (cf. Epistemology above). Hooker (2011c) argues against this that the notion arises only from inappropriate reliance on logical structures, that it thus imports an arbitrary human fiat, and anyway that dynamical distinctions within a larger dynamical process ontology suffice to understand the science within a single systems ontology. This applies to understanding explanation (below) and much else.

3 - This discussion should make clear that I regard all these dichotomist theories as simple first approximations to be succeeded by richer systems process models. In what follows I use the term 'paradigm', but without Kuhn's sharp logical/non-logical dichotomy and so without either the incommensurability or the internal globalness of each stasis. 


\section{RE-MODELLING SCIENTIF- IC CHANGE: COMPLEX SYS- TEMS FRAMES INNOVATIVE PROBLEM SOLVING}

phy, electron- and neutron- microscopes) native perception, a process that both hugely supports science and is supported by science and continues to expand. (II) Technology. Perception and other technologies (digital, telemetry, quantal, ...) have both improved scientific capacity for research (video recording of data, radio astronomy) and been transformed by scientific insight (e.g. mathematics of cryptography and reliable signalling). (III) Proto-theory (kinematics of mechanics, generalised formal and statistical inference, etc.) provides ever richer possibility frameworks to support scientific theoretical and methodological development, and stimulate further proto-theoretic framework development. These three frameworks have each developed somewhat independently of science, having rich lives in the wider economy (e.g. ultra-sonography in medicine, lasers in building) and each is also partly self-regenerative and self-improving (e.g. lasers created new demands for their use, in turn leading to development of new and improved kinds of lasers). Between them they frame scientific activities and sustain their improvement and expand their scopes while scientific advance in turn feeds their own development.

PFrame 2. The science-PFrame 1 inter-relationships form the first of two inter-locked positive reinforcement processes, scientific and societal. (I) PFrame 1 inter-relationships. It has already been remarked above how new technologies (perceptual and other) and new proto theories provide science with new instruments and other methods and so stimulate its further development, while developing science provides new and/or improved technologies and methods, thus stimulating their development in the wider economy as well as in science, which in turn creates wealth that partly also feeds back to the economic (and cultural) support of science. Considering for convenience proto theory as an intellectual technology, call this dynamic science-PFrame 1 reinforcement system the science-technology change machine. (II) Three inter-locked institutional transformations form the societal change machine: (i) An economic transition from traditional hierarchical fixed economies like feudalism to a market economy, where exploitation of novelty provides wealth opportunity, the only source of security. (ii) A political transition from the inherited power structure of archbishop and king to that of representative democracy, where political saleability provides power opportunity, the only security. (iii) A religious transition from the traditional communal Catholic Church to individualist Protestant churches, where personal relation to the divine is the only security, removing church constraint. All three open up the future, emphasising individual opportunity and lowering social resistance to change. Together they unleashed massive societal change, itself supported by a flow of new ideas and technologies from science, and also feed back to support science for its generation of new capacities. These two great change machines, I + II, are mutually reinforcing and have been increasing in size and speed for 400 years now, transforming science and all societies.

PFrame 3. Three inter-locked developmental processes: under- standing the empirical world, understanding our understanding processes and understanding the conditions of scientific flourishing. As perception illustrates, science studies us as well as the larger natural world, producing a science-amenable understanding of both. All three understandings emerge essentially through problem solving processes (see below), however the latter two are as often in tension with, as supportive of, market imperatives.

In addition, there are three factors complicating any attempt at systems modelling of science. (1) In the dichotomous analytic world the cognitive moves (prediction, explanation, etc.) are confined to a closed world of logical inference, but not so in the integrated naturalistic world of modelling here. And in fact all of the long-term processes above can operate in a pragmatic, physical mode, which is at least a-epistemic and may be non-cognitive. For example, a magnifying lens can also become a heat concentrator through physical placement, perhaps by accident or undirected play; whatever the case, at the time this act runs outside of rational scientific conceptualisation and investigation, introducing cognitively un-regulated novelty to science. (It may be captured for science in retrospect.) Likewise, technological development in the market place may remain within the broadly cognitive, qua strategic, but for the most part it is economically driven, not epistemically driven; so when its products filter back into science it can again form a source of un-regulated novelty for science. These sources subvert the use of wholly internal, cognitive conceptual-strategic models of scientific process, such as has been encouraged by the purely logico-inferential model of scientific method, leaving its processes a mix of epistemic rational, non-epistemic strategic rational, and a-rational. ${ }^{4}$ (2) Science involves specialised interactions that reach out beyond the immediate research context, e.g. from a biologist to a chemist or mathematician, and outlier risk-taking strategies that traverse collective agreements, e.g. those agreements for supporting a current disciplinary research foci. Both features are often ephemeral but crucial to dynamics. Also, as science expands and complexifies it is driven to construct ever more complex multi-disciplinary, multi-national, moderately long-lived, research arrangements that further mediate scientist-scientist linkages. ${ }^{5}$ (3) Scientists have many highly conditional, meta-stable commitments that can be triggered to shift by highly specialised signals, the consequences spreading throughout the rest of science, in part via (1) and (2). ${ }^{6}$

To all this must be added all the more familiar shorter term processes of laboratory activity, conference and journal presentations and disputes, etc. Given these complications it is unsurprising to find theories purporting to rise above the detail to capture the essential process of science. The commonest ways philosophers of science attempt this is to argue for a distinct, higher order realm of normatively binding procedures, notably logic, whose use distinguishes science as an enterprise uniquely focused on the epistemic goal of truth. However, as already not-

4 - These non-cognitive elements can also occur within scientific methods, e.g. hand cutting to a physical pattern (a drawing, etc.) versus using an equivalent digital pattern to drive an electric saw. While outcome equivalent, the distinction between the two methods is important, e.g. they offer very different learning possibilities.

5 - A good example is the discussion by Ankeny and Leonelli (2016) of what they call repertoires, and references to many other ideas therein. While their approach risks cognitive/epistemic direction being lost in the detail, analyses like Andersen (2016) run the reverse risk of failing to notice such structures, but also contribute interesting more global features to modelling.

6 - Note that the foregoing offers a holistic product-of-processes characterisation of science quite different to decomposition into products of weakly interacting parts, e.g. Simon's near-decomposability (1982), and decomposition into mean-field and fluctuation dynamics, e.g. in the bio-econo-social sciences - see Auyang (1998). 
REVUE

DE LA SOCIÉTÉ

DE PHILOSOPHIE

DES SCIENCES

\section{RE-MODELLING SCIENTIF- IC CHANGE: COMPLEX SYS- TEMS FRAMES INNOVATIVE PROBLEM SOLVING}

ed, the approach has proven deeply inadequate to its purpose (see below). This frees us up to consider instead systems dynamic approaches to the issue. Here are brief comments on three of these: organic (macro organisational), evolutionary (macro populational), self-organisational (micro-macro emergentist).

(1) Organic modelling includes viable system and autonomy versions, each claiming that features of internal organism organisation, respectively (a) parts with organ-like functions (digestion, toxin removal, etc.) and (b) a capacity to wholly regenerate oneself, must also apply to science as a whole. See e.g. and respectively Espejo and Harnden (1989) and Moreno and Mossio (2016). But in each case it is obscure how their core requirement, even were it granted, might illuminate scientific cognitive processes and the correlative diverse institutional roles that embody them. (Within the (b) variant, a successful defence of closure as constituting semantic information might provide an exception - the issue is left open here.) (2) A minimal evolutionary process occurs wherever there is a VSR (variation, selection, retention) process which, abstracting from requiring a genetic basis, is nearly universal. Without the appropriate embedding infrastructure (e.g. bird physiology undergirding flight) it is uninformative; with it, it is highly specific. Again, how to apply these models? What illumination would follow? (3) Self-organisation is a recognised process; a common example is where increased throughput induces specialisation. Science will show many such instances, and Shi contends that the public cognitive rules for science self-organise from the economic roles of scientists as investors, entrepreneurs, and project managers in research. See Shi (2001), cf. van der Leeuw's (2004) principle that institutions emerge from individual action, also Hooker (2011b, §5.3). Shi’s contention has major consequences for understanding science generally (see below), but these are again higher order uniformities, they do not yet illuminate its diverse detail. 7 The questions remain: How to apply the models? What illumination would follow? In sum, while aspects of these three higher order processes may well apply to science (in fact surely must apply, at least in part), they cannot provide in themselves an adequate basis for modelling scientific activities.

In consequence of its wide variety of scales for key processes, coupled with their idiosyncrasy to problem, methods, etc. and all the other considerations noted above under PFrames 1, 2 and 3 , plus an absence of appropriate theoretical models generally, science is currently recalcitrant to modelling, and will perhaps always remain so beyond some highly general modelling like that above and some more specific modelling (see e.g. note 7).

\subsection{Q3(II): Consequences for formulating a paradigm of scientific understanding}

\subsubsection{From logic to problem solving}

In understanding science we minimally want to know how it produces informative, reliable and usable outcomes through a rational process. Scientific epistemology then revolves around having a method capable of delivering these valuable outcomes. From a systems perspective, an answer should specify a process that is as effective at delivering the desired valuable outcomes as is reasonable for finite, fallible inquirers and that can be adapted to apply to each research context in ways that model science as a stable, productive, but also highly adaptable, system. But, cutting all that off, traditional analytic philosophy has, as noted under Q3(I), a quick, neat, very different answer: method is logical deduction, that guarantees its rationality, and, since deduction is truth preserving, it equally guarantees that all output deduced from true factual inputs (basic data) will in turn be true.

However, logic alone is multiply inadequate to this role, for reasons now well understood. (a) Data are not guaranteed true, rather they are fallible, potentially containing both errors of detail and larger built-in errors of presupposition. Both defects require critical investigation of data as much as does any other part of science. (b) Deductive inference is conceptually non-creative, so cannot encompass theoretical concepts, and it is non-ampliative, so cannot even encompass generalisation. (c) The stark separation of method as a priori and normative from a posteriori empirical data and theory runs against the massive interaction between method and science over the history of science. And so on. Attempts to generalise logic to repair these inadequacies have never succeeded and arguably cannot do so. (See note 9 below.)

So, rejecting a priorism for finitist, fallibilist, naturalism in which norms are learned as theories of how best to flourish, we search for a conception of method that should be applicable throughout science, focused on rational epistemic improvement, grounded in actual competencies of science, and itself along with science be fallibly improvable. Cutting a long story short, I suggest the most satisfying candidate is problem solving. Problems abound in science: How to accurately and reliably detect this condition? Test this theory? Generalise this pattern? Apply this molecule to achieve a cure? Scientists are constantly faced with such problems and manage to solve many of them more or less satisfactorily, the point of doing so being to improve our knowledge, our instruments, etc. etc. Method becomes how we go about rationally solving problems. The account of problem solving I shall give is itself rooted in the study of problem solving processes, in particular research into design and science problem solving and aspects of cognitive psychology. With norms considered fallible, constructed theories concerning how to flourish, we have a virtuous upward spiral in which epistemic theory improves science, which in turn improves epistemic theory and through the same problem solving processes. ${ }^{8}$ Indeed, and finally, we shall see (below) how that kind self-improvement stands at the core of problem solving processes and uniquely creates expertise. Self-improvement is its fallible, but essential, competence.

\subsubsection{Naturalist non-formal rationality}

The naturalist account of rationality required for a theory of rational problem solving comes in two forms, an Outer Form of natural rationality [OFNR], a more general form that provides the fundamental resources for reason and a basic task orientation to their use, and a more specific Inner Form of natural rationality [IFNR], though still universally applicable, that models the generic internal structure of the rational problem solv- 


\section{RE-MODELLING SCIENTIF- IC CHANGE: COMPLEX SYS- TEMS FRAMES INNOVATIVE PROBLEM SOLVING}

ing process. Call the model a Universal Problem Solving [UPS] process. Arguably the UPS provides the most detailed but still universally general model of rational problem solving. After that one obtains more specific models of rational problem solving in specific subfields and interdisciplinary matrices, obtained by loading more specific constructs into the IFNR, from disciplinary paradigms to Ankeny/Leonelli-style repertoires (note $5)$.

OFNR. In the exercise of reason, there are four principal resources or means for the improvement of judgement: observation, forms of reasoning (formal and non-formal), constrained but creative construction, and critical appraisal. These four bundles of processes are utilised by both individuals and communal groupings of various kinds: in science by scientists, laboratories, learned societies, collaborative and discussion groups, universities, etc. Each of these four domains generates a set of constraints on rational procedure and these constraints mutually interact in complex ways. For instance, observation requires perceptual accessibility, balance, etc. and the requirement for systematic critical appraisal may lead to introducing new persons to an evaluation process, persons that synergistically also add to the variety of observations brought to bear on the situation. Each of these four means of improving judgment will contribute to both elaborating reasons for, and critical challenges to, our judgements, leading to improved judgements, and each of them will also play various roles in developing our rational skills further. ${ }^{9}$

The ideal of reason is the unlimited use of the instrument by which we seek to transcend present imperfections. Thus, the ideal of reason is to increase without limit the acquiring of relevant observational data, the canvassing of relevant reasons, the creative construction of relevant structures and processes and subjecting all to critical appraisal. The working standard is to pursue the ideal to the maximum feasible extent. It is the right kind of rationality ideal and standard for finite imperfect creatures. It also satisfies the requirements of a Kantian regulatory ideal, namely to be ideally rational is desirable, it is possible to move towards the ideally rational state, and doing so has desirable consequences.

IFNR. As noted above, the UPS model emerged from the unification of several lines of inquiry into problem solving process, namely in design, science, psychology and biological organisation and has been presented in some detail elsewhere..$^{10}$ It suffices for present purposes to simply present its main features with brief illustration. The UPS model recognises five main foci of formulation and re-formulation that characteristically occur during a problem solving process: problem formulations, solution formulations, methods, data indicating constraints on the system, and partial solution proposals. Each of these represents a kind of possibility: possible problem formulations, possible solution formulations, etc. A bundle of possibilities, one drawn from each node, represents a possible framework for conducting a problem solving trial. But possibilities are interrelated across nodes, so that coherent frameworks are much fewer. It is these latter that form the base layer organising the UPS process. In the problem solving process each and all of these five nodes may alter their focal possibility several times.

Consider, in simplified illustration, the design of a new bank branch. There will be established designs for the usual 'shop front' branch but it soon emerges these don't work on the square lot available. The designer tries modifying the standard linear arrangement, but none are satisfactory. By now the problem has shifted from 'fit a standard design' to 'find a layout that fits all functions to the space', to 'find a branch organisation that accommodates a square lot (without sacrificing functions)', the solution criteria have changed accordingly - to, say, 'minimise congestion and leave all functions accessible' - as have the partial design proposals tested. Again finding no satisfaction, the designer then 'relaxes' the implicit constraint to a single, street-level design, to allow some functions to be located on higher floors. This move would reduce upstairs tenant income and increase demand for vertical movement (elevators, stairs) and customer pathway guidance. But besides including all standard functions, this arrangement also offers increased customer capacity to follow idiosyncratic paths, and opportunity to contact extended customer services (e.g. architect, project management, legal and taxation services). It also requires obtaining new data on customer banking needs and movement assistance and new methods to analyse and plan customer paths and provide access, along with problem reformulation to 'Find a design that effectively utilises multi-floor, multi-path banking.' Method might now aim for minimisation of average path length and/ or transit time and optimisation of interaction with appropriate non-banking functions. All up we now have a substantial shift in all five design possibility nodes, problem and correlative solution formulations, method, constraints and trial partial solution proposals. This amounts to a re-orienting shift to a whole-ofbuilding, integrated services design approach. The example illustrates how one iteration of problem solving prepares the ground for its successor and how revolutions can arise rationally if powerful enough problem solving options and information are available, without necessary appeal to genius insights. (See e.g. Koestler 1959.)

But none of this will support improvement unless there is some way to learn from problem solving, and learning presupposes a way to remember the relevant moves and outcomes. So, for each problem, each node is equipped with a memory of its possibilities tried and their outcome values contributed, each such entry tagged to the framework used. The point of this is to identify trends in value produced, the direction(s) of increasing failure, to be avoided, and of increasing success, to be pursued through choice of suitably modified frameworks. But frameworks span the 5 nodes, so what is ultimately needed is an integrated mem-

\footnotetext{
9 -See further Hooker $(1995 b, 2009,2010)$. That they are the only kinds of resources available to improve judgement is itself a fallible judgement subject to re-examination as our understanding of reason improves. For a more detailed examination of them, see Hooker (2010) and also, Hoffmaster and Hooker (2017), which is devoted to showing how OFNR expands and enriches ethical judgement formation, and largely confines itself to that account.

10 - For more on the proposed UPS see Hooker (2017). For its background see respectively Farrell and Hooker (2007a, b, 2009) (science), Farrell and Hooker (2012, 2013, 2014, 2015) (design), Christensen and Hooker (2000, 2002) (bio-organisation). For a direct connection to the psychology of problem solving expertise, see e.g. Christensen et al. (2015, 2016). The cognitive psychology or science of problem solving has a rich history, with many important insights gained. For a general introduction to the twentieth century work see e.g. the Wikipedia entry under 'Problem Solving'. Various parts of the problem solving process presented here have echoes in that history, e.g. the emphasis on the construction of higher order, more generic knowledge here references Simon's original idea oflearning by doing (Newell and Simon 1972, Simon 1996).
} 


\section{RE-MODELLING SCIENTIF- IC CHANGE: COMPLEX SYS- TEMS FRAMES INNOVATIVE PROBLEM SOLVING}

ory across the nodes that can track overall framework value created. Then as problem solving proceeds the possibility nodes are re-visited, in various orders as their outcome trends in coherent frameworks indicate. Eventually, a coherent framework, or several closely related frameworks, emerge that deliver superior outcome value against outcome criteria, and one is developed and adopted as the solution.

Investigator knowledge for a particular problem solved includes the variety of relevant frameworks, their occasions of use and their performances. This knowledge can subsequently be drawn upon to adapt frameworks, that is, problem formulations, methods, etc., to suit new problem circumstances. In this way investigators become increasingly better equipped to pursue solutions as they accumulate specific investigatory experience, both successful and not. That is, they develop expertise. This provides a model of the specific structures of expertise, its applications and limits.

In this organisation of learning, while investigators are learning to solve particular problems, they are also learning the nature of the class of problems and how to solve them. This double learning is the key to the problem solving power of the process. For instance, because investigators are now more sensitively attuned to how to investigate, in particular understanding the possible sources of success and failure, they will also be that much sharper at recognising and evaluating (learning) new particular sources of success and failure posed by new specific problems. In short, by learning a higher-order characterisation of the problem class they will have been learning how to learn about problem solving in the domain while learning how to solve specific problems. This doubly integrative higher order structure (within and between nodes), fed back to improve problem solving, is the fundamental bootstrap required for all learning to be improvable. It forms the key to understanding the organisation and power of the problem-solving process.

Furthermore, this process allows the rational resolution of initially ill-defined problems, problems whose formulation and structure is vague, gappy or ambiguous, or tacitly internally conflicted, or whose valid methods are unsure, like how to marry well, or validly test a theory in a new domain. Such problems of necessity lie at the root of every new problem solving domain. Ill-definedness is equivalent to the absence of identified and evaluated possibilities at one or more nodes. These deficiencies are corrected essentially by adding the missing information piecemeal, and then filling in intra- and inter- node integration, as trials proceed. The bank branch designer faced an initially ill-defined problem in respect of the relevant constraints and methods, but overcame the consequent procedural difficulties through filling in new possibilities as the investigation proceeded, brought about by introducing new constraints (multi-storey) and expanding and adapting methods. These processes can take from minutes to months to decades or even centuries. ${ }^{11}$

This UPS process also captures the basic bio-organisation of intelligence. The bootstrap process organisation uniquely realises Self-Directed Anticipative Learning (SDAL), the higher order capacity to use feedback from action (trials) to adapt the process of forming adaptations. That is, it is to exercise adaptability, especially cognitively-based behavioural adaptability, and to do so in a way that is substantially in the control of the agent (self-directed) and oriented to anticipating relevant, normatively assessable, feedback. Adaptability is achieved through use of the higher order generic knowledge for the domain to modify the strategies for problem solving to suit the context. SDAL is arguably the fundamental organisational marker of intelligence and was shown to lie at the heart of the improvement process in Ape language research (note 10).

\subsubsection{Assessing the UPS process}

It is time to briefly assess the proposed UPS process. First, it is not a machine, not a formal programme, does not require a strictly ordered state sequence, not even with deterministic node decisions, and not self-contained. But it supplies the model that grounds all learning and it utilises only a small set of generic features, specialised by context, to do so. It provides the basic learning bootstrap, powerful enough to solve ill-defined problems, powerful enough to rationalise revolutionary transitions. It specifies a universal process, so unifying science process with design process and similarly all cognate learning domains (law, ethics, sleuthing, ...). And it is grounded in design research, cognitive psychology, a study of research into ape language and many other intuitive examples, and put to work in an extended examination of applied ethics (Hoffmaster and Hooker 2017).

Now it is time to pull all the strands together to see if they make at least the beginnings of a different and improved paradigm for understanding science. The formalist paradigm was a failure from the outset, it did not need complex systems to show it so. But the growing awareness of complexity issues helped point in another direction, to understanding science as a dynamical learning process in a complex epistemic system (and design, law, ethics ...analogously). The model here is the proposed new systems explanatory paradigm noted under Q2: between the preceding staircase of sequential stages and the succeeding systems dynamical process perspective there is a deep shift in the explanatory questions asked, plus the refusal to exclude any condition from requiring explanation.

Root conception of science: not a machine generating logical truths, but a complexly organised net of fallible problem solving (UPS) processes running on a wide range of spatial and temporal scales, and that improves itself: data, methods, theories, instruments and goals, and institutions. Its SDAL bootstrap drives scientific learning. Improvement includes performance against the epistemic values - for example, reliability, precision, accuracy, applicability/ manipulability, breadth and depth, each applying to data, methods, theories and instruments - and improvement of those value categories themselves, along with improvement of the local pragmatic proxy goals through which we pursue them.

Root conception of rationality: not applied formal reason, but a non-formal process of producing improvement through

11 - Or be unresovable. It is easy to specify external conditions that render problems insoluble, e.g. requiring a solution in much less time than it takes to study the dominant dynamics to the required reliability. These should not count against any UPS process. Even here our proposed UPS process will have rich resources with which to negotiate a problem transform that permits a more coherent response. As for difficult identification of missing possibilities, it is fair to suggest that every outstanding unification problem in physics, for example of relativity and quantum mechanics, is an ill-defined problem of this sort. 
REVUE

DE LA SOCIÉTÉ

DE PHILOSOPHIE

DES SCIENCES

\section{RE-MODELLING SCIENTIF- IC CHANGE: COMPLEX SYS- TEMS FRAMES INNOVATIVE PROBLEM SOLVING}

applying, to the maximum feasible extent, the resources of observation, reasoning, creative construction and critical appraisal within UPS structures. The primary object of rationality is process: outcomes are rational if they are the result of a rational process. The recognition that the UPS is successful cognition then grounds a (fallible, revisable) methodological norm of full use of that UPS in science (modulo correction for science-revealed biases and errors).

Traditional methods: the coherent integration of the classic philosophies of method [induction, falsifiability, ... ], is achieved by now treating them as variously useful learning policies for pursuing the epistemic values. All of these pursuits potentially conflict, requiring compromise and/or institutional spread of alternative pursuits to spread normative risk. (See e.g. Hooker (1981) for an initial discussion, Herfel and Hooker (1996, 1999), Hooker (2003) for earlier work on a systems perspective, with Andersen (2016) adding a recent perspective.)

Scientific roles: scientists act as epistemic entrepreneurs, investors, project managers and consumers, of valuable knowledge and expertise and the epistemic rules governing epistemic pursuit and assessment of valuable knowledge emerge from these pursuits as a higher order knowledge, this time of institutional epistemic design built up over many trials. This provides an 'internal' conceptualisation or modelling of what drives the research process and how it is organised, the making of a new paradigm for that activity. But it does not reduce the recalcitrant aspects (above) of modelling the external, institutionalised process. There is no principled barrier to conjoining the two models, and doing so will be required for a completed paradigm.

\section{5-Conclusion}

The advent of complex systems brings with it fundamental challenges and changes throughout our understanding and use of science.

\section{ACKNOWLEDGMENTS}

Thanks to Christian Sachse for insightful comments on an earlier draft and for gracefully hosting my participation at all stages. I acknowledge the work of several doctoral/post-doctoral research associates (see those whose names appear in joint references herein + John Collier, Kai Hahlweg, and Yanfei Shi) whose successive contributions have ultimately made this paper possible.

\section{REFERENCES}

ANDERSEN, Hanne. 2016. Collaboration, interdisciplinarity, and the epistemology of contemporary science. Studies in History and Philosophy of Science Part A, 56, 1-10. Link

ANKENY, Rachel, LEONELLI, Sabina. 2016. Repertoires: A post-Kuhnian perspective on scientific change and collaborative research. Studies in History and Philosophy of Science Part A, 6o, 18-28. Link

AUYANG, Sunny. 1998. Foundations of complex-system theories in economics, evolutionary biology and statistical physics. Cambridge: Cambridge University Press. Link
BRINSMEAD, Thomas, HOOKER, Cliff. 2011. Complex systems dynamics and sustainability: conception, method and policy. In HOOKER, Cliff. Philosophy of complex systems. Handbook of the philosophy of science, Vol. 10. Amsterdam: Elsevier. 80938. Link

CHRISTENSEN, Wayne, HOOKER, Cliff. 2000. An interactivist-constructivist approach to intelligence: self-directed anticipative learning. Philosophical Psychology, 13(1), 5-45. Link CHRISTENSEN, Wayne, HOOKER, Cliff. 2002. Self-directed agents. Naturalism, Evolution and Intentionnality. Canadian Journal of Philosophy, Special Supplementary Volume 27, 1952. Link

CHRISTENSEN, Wayne, BICKNELL, Kath, MCILWAIN, Doris, SUTTON, John. 2015. The Sense of Agency and Its Role in Strategic Control for Expert Mountain Bikers. Psychology of Consciousness: Theory, Research, and Practice, 2(3), 340-53. Link CHRISTENSEN, Wayne, SUTTON, John, MCILWAIN, Doris. 2016. Cognition in skilled action: meshed control and the varieties of skill experience. Mind \& Language, 31, 37-66. Link

CLEMENTS, Frederic. 1928 [1973]. Plant Succession and Indicators. New York: Wilson.

ESPEJO, Raul, HARNDEN, Roger (eds.). 1989. The viable system model: interpretations and applications of Stafford Beer's VSM. Chichester: Wiley.

FARRELL, Robert, HOOKER, Cliff. 2007a. Applying self-directed anticipative learning to science I: agency and the interactive exploration of possibility space in Ape language research. Perspectives on Science, 15(1), 86-123. Link

FARRELL, Robert, HOOKER, Cliff. 2007b. Applying self-directed anticipative learning to science II: learning how to learn across 'revolutions'. Perspectives on Science, 15(2), 220-53. Link FARRELL, Robert, HOOKER, Cliff. 2009. Error, error-statistics and self-directed anticipative learning. Foundations of Science, 14(4), 249-71. Link

FARRELL, Robert, HOOKER, Cliff. 2012. The Simon-Kroes model of technical artifacts and the distinction between science and design. Design Studies, 33(5), 480-95. Link

FARRELL, Robert, HOOKER, Cliff. 2013. Design, science and wicked problems. Design Studies, 34(6), 681-705. Link

FARRELL, Robert, HOOKER, Cliff. 2014. Values and norms between design and science. Design Issues, 30(3), 29-38. Link FARRELL, Robert, HOOKER, Cliff. 2015. Designing and sciencing: reply to Galle and Kroes. Design Studies, 37(1), 1-11. LinkGAO, Yin, HERFEL, William. 2011. Constructing post-classical ecosystems ecology: the emerging dynamic perspective from self-organising complex adaptive systems. In HOOKER, Cliff. Philosophy of complex systems. Handbook of the philosophy of science, Vol. 1O. Amsterdam: Elsevier. 389-419. Link

GOULD, Stephen, ELDREDGE, Niles. 1977. Punctuated equilibria: the tempo and mode of evolution reconsidered. Paleobiology, 3 (2), 115-51. Link

GUNDERSON, Lance, HOLLING, Crawford (eds.). 2002. Panarchy : understanding transformations in human and natural systems. New York: Island Press.

HERFEL, William, GAO, Yin, RODRIGUES, Dianah. 2011. Chinese medicine and complex systems. In HOOKER, Cliff. Philosophy of complex systems. Handbook of the philosophy of science, Vol. 10. Amsterdam: Elsevier. 675-721.

HERFEL, William, HOOKER Cliff. 1996. Cognitive dynamics and the development of science. In GINEV, Dimitri, COHEN, 
REVUE

DE LA SOCIÉTÉ

DE PHILOSOPHIE

DES SCIENCES

\section{RE-MODELLING SCIEN- TIFIC CHANGE: COMPLEX SYSTEMS FRAMES INNOVA- TIVE PROBLEM SOLVING}

Robert S. (eds.). Issues and images in the philosophy of science. Boston Studies in the Philosophy of Science. Vol. 192. Dordrecht: Springer. 127-72. Link

HERFEL, William, HOOKER, Cliff. 1999. From Formal Machine to Social Colony: Toward a Complex Dynamical Philosophy of Science. In CHIARA DALLA, Maria Luisa et al. (eds.). Language, Quantum, Music. Synthese Library. Vol 281. Dordrecht: Springer. 7-18. Link

HOFFMASTER, Barry, HOOKER, Cliff. 2017. Re-reasoning Ethics. Boston, Massachusetts : MIT Press.

HOLLAND, John. 1992. Adaptation in natural and artificial systems. Cambridge, Massachusetts : Bradford/MIT Press.

HOOKER, Cliff. 1981. Formalist Rationality: The Limitations of Popper's Theory of Reason. Metaphilosophy, 12, 247-66. Link HOOKER, Cliff. 1994. Regulatory Constructivism: On the Relation Between Evolutionary Epistemology and Piaget's Genetic Epistemology. Biology and Philosophy, 9, 197-244. Link

HOOKER, Cliff. 1995a. Critical Discussion of J. H. Holland. Adaptation in natural and artificial systems. Philosophical Psychology, 8, 287-99.

HOOKER, Cliff. 1995b. Reason, regulation and realism. Albany, New York : SUNY Press.

HOOKER, Cliff. 2003. Science: legendary, academic - and post-academic?. Minerva, 41(1), 71- 81. Link

HOOKER, Cliff. 2009. Interaction and bio-cognitive order. Synthese, 166(3), 513-546. Link

HOOKER, Cliff. 2010. Rationality as effective organisation of interaction and its naturalist framework. Axiomathes, 21, 99-172. Link

HOOKER, Cliff. (ed.) 2011a. Philosophy of complex systems. Handbook of the philosophy of science, Vol. 10. Amsterdam: Elsevier.

HOOKER, Cliff. 2011b. Introduction to philosophy of complex systems. Part A: Towards a framework for complex systems. In HOOKER, Cliff. Philosophy of complex systems. Handbook of

\section{HISTORIQUE}

Article initialement soumis le 8 novembre 2016.

Version révisée soumise le 15 septembre 2017.

Article accepté le 15 septembre 2017.

SITE WEB DE LA REVUE

sites.uclouvain.be/latosensu/index.php/latosensu/index

ISSN 2295-8029

DOI HTTP://DX.DOI.ORG/10.20416/LSRSPS.V5I1.2 the philosophy of science, Vol. 10. Amsterdam: Elsevier. 3-90. Link

HOOKER, Cliff. 2011c. Introduction to philosophy of complex systems. Part B: Scientific paradigm. In HOOKER, Cliff. Philosophy of complex systems. Handbook of the philosophy of science, Vol. 1o. Amsterdam: Elsevier. 843-912. Link HOOKER, Cliff. 2017. A proposed universal model of problem solving for design, science and cognate fields. New Ideas in Psychology, 47, 41-8. Link

HOOKER, Giles, HOOKER Cliff. 2018. Machine Learning and the Future of Realism. Spontaneous Generations: A Journal for the History and Philosophy of Science, 9(1) Forbes, C. Ed. The Future of the Scientific Realism Debate: Contemporary Issues Concerning Scientific Realism. 174-182. Link

KOESTLER, Arthur. 1959. The sleepwalkers. London: Hutchinson.

MORENO, A., MOSSIO, M. 2016. Biological autonomy: a philosophical and theoretical enquiry. Dordrecht: Springer. Link NEWELL, Allen, SIMON, Herbert A. 1972. Human problem Solving. New Jersey : Prentice-Hall.

PIAGET, Jean. 1957. Construction of reality in the child. Translated by M. Cook. London: Routledge \& Kegan Paul.

SHI, Yanfei. 2001. The economics of scientific knowledge: a rational choice institutionalist theory of science. Cheltenham: Edward Elgar.

SIMON, Herbert A. 1982. Models of bounded rationality. Vol. 3. Cambridge, Massachusetts : MIT Press.

SIMON, Herbert A. 1996. The sciences of the artificial. $3^{\text {rd }}$ ed. Cambridge, Massachusetts : MIT Press.

TOULMIN, Stephen. 1961. Foresight and Understanding an Enquiry into the Aims of Science. Bloomington, Indiana : Indiana University Press.

VAN DER LEEUW, Sander. 2004. Nonlinear processes and archaeology. In RENFREW, Colin, BAHN, Paul (eds.). Key concepts in archaeology. London: Routledge.

\section{CONTACT ET COORDONNÉES}

Cliff Hooker

Education \& Humanities, University of Newcastle, Newcastle, NSW, Australia 2308

Cliff.Hooker@newcastle.edu.au

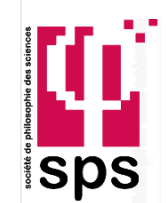

SOCIÉTÉ DE PHILOSOPHIE DES SCIENCES (SPS)

École normale supérieure

45 , rue d'Ulm

75005 Paris

www.sps-philoscience.org

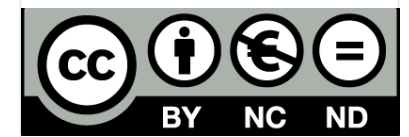

